\title{
Brand attitude pasien rawat inap terhadap minat pemanfaatan kembali pelayanan di rumah sakit
}

\author{
Heriyati $^{1}$, Syahrir A Pasinringi ${ }^{2}$, Indahwaty Sidin ${ }^{2}$ \\ ${ }^{1}$ Fakultas Ilmu Kesehatan, Universitas Sulawesi Barat \\ ${ }^{2}$ Fakultas Kesehatan Masyarakat, Universitas Hasanuddin
}

\section{Keywords :}

cognitive, affective and interest to reuse

\section{Kontak :}

Heriyati, S.KM, M.Kes

Email : heriyati@unsulbar.ac.id

Fakultas Ilmu Kesehatan, Universitas

Sulawesi Barat

Vol 2 No 1 September 2019

DOI: https://doi.org/10.31605/jhealt.v2i1

(C)2018J-Healt

ini adalah artikel dengan akses terbuka dibawah licenci CC BY-NC-4.0

https://creativecommons.org/licenses/by-nc/4.0/

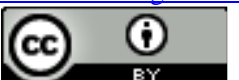

\begin{abstract}
Abstrak
Sikap terhadap merek, didefinisikan sebagai evaluasi keseluruhan tentang produk yang dilakukan oleh konsumen. Penelitian ini bertujuan untuk mengetahui hubungan brand attitude pasien rawat inap terhadap minat pemanfaatan kembali pelayanan di Rumah Sakit Universitas Hasanuddin. Penelitian ini menggunakan rancangan survei analitik dengan pendekatan cross sectional study. Cara pengambilan sampel secara purposive sampling yaitu teknik penentuan sampel dengan pertimbangan tertentu dengan syarat pasien telah dirawat lebih dari dua hari dengan besar sampel 120. Analisa data yang dilakukan adalah univariat dan bivariat dengan menggunakan tabel distribusi frekuensi dan uji korelasi. Hasil penelitian ini menunjukkan ada hubungan kognitif terhadap minat pemanfaatan kembali pelayanan $(p=0,001)$, dan ada hubungan afektif terhadap minat pemanfaatan kembali pelayanan $(p=0,049)$. Terdapat hubungan variable kognitif dan afektif terhadap minat pemanfaatan kembai pelayanan di Rumah Sakit. Disarankan agar pihak rumah sakit terus meningkatkan kualitas pelayanan melalui pelatihan sumber daya manusia dan melengkapi sarana pendukung fisik yang belum ada. Melakukan penyebaran informasi mengenai keberadaan Rumah Sakit Universitas Hasanuddin pada wilayah di luar kota Makassar.
\end{abstract}

\section{Abstract}

Brand attitude, is defined as the overall evaluation of the product carried out by consumers. This study aims to determine the brand relationship attitude of inpatients to the interest of reuse of services at Hasanuddin University Hospital. This study uses an analytical survey design with a cross sectional study approach. The method of sampling was purposive sampling, which was the technique of determining samples with certain considerations, provided that the patients had been treated for more than two days with a sample size of 120. The data analysis was univariate and bivariate using frequency distribution tables and correlation tests. The results of this study indicate that there is correlation cognitive to the interest in reusing services $(p=0.001)$, and there is correlation affective to the interest in reusing services ( $p=$ 0.049). There is a relationship between cognitive and affective variables towards interest to reuse services at hospital. It is recommended that the hospital continue to improve the quality of services through human resources training and complete physical support facilities not yet available, do information dissemination about the existence of Hasanuddin University Hospital in areas outside the city of Makassar. 


\section{PENDAHULUAN}

Di era globalisasi sekarang ini, pengimplementasian akan pelayanan yang berkualitas sangat dibutuhkan untuk melihat sejauh mana sikap konsumen dalam pemanfaatan pelayanan rumah sakit. Maka dari itu, para penyedia layanan harus selalu mengikuti dan mempelajari perkembangan perilaku konsumen, serta harus mempunyai pengetahuan yang baik mengenai perilaku konsumen sehingga dapat memberikan informasi yang akan digunakan untuk menemukan peluang-peluang dalam pemasaran, dan dapat menetapkan strategi pemasaran yang tepat.

Perilaku konsumen mempelajari faktor-faktor yang mempengaruhi perilaku konsumen itu sendiri seperti faktor budaya, sosial, kepribadian dan psikologis (Kotler dan Keller,2009). Dalam faktor psikologis, terdapat beberapa komponen dan salah satunya adalah sikap.

Rumah Sakit Universitas Hasanuddin merupakan salah satu rumah sakit di kota Makassar. Berdasarkan data yang didapatkan diketahui kepuasan pasien rawat inap yang fluktuatif yakni pada triwulan 1 tahun 2012 sebesar $80 \%$, triwulan 2 sebesar $91 \%$, triwulan 3 sebesar $76 \%$ dan triwulan 4 sebesar $100 \%$ (Hospital Safety Rumah Sakit Universitas Hasanuddin, 2012). Dengan adanya ketidakpuasan dari konsumen juga dapat berpengaruh terhadap sikap konsumen dalam memanfaatkan pelayanan berikutnya di rumah sakit.

Adanya keluhan dari pasien rawat inap atau keluarga pasien mengenai pelayanan medis sebanyak 6 keluhan, pelayanan paramedis 2 keluhan, kebersihan dan kenyamanan 17 keluhan, mengenai informasi ada 5 keluhan dan pelayanan penunjang medis sebanyak 6 keluhan, keluhan tersebut sebagian besar mengenai hal-hal sebagai berikut, yaitu rusaknya fasilitas di ruang rawat inap seperti AC dan TV, pada pelayanan penunjang medis pasien mengeluhkan keterlambatan hasil dari instalasi laboratorium dan radiologi, pasien juga mengeluhkan sulitnya bertemu dengan dokter serta informasi penjadwalan operasi yang kadang berubah (Customer Care Rumah Sakit Universitas Hasanuddin, 2012). Keluhan tersebut dapat mempengaruhi sikap konsumen untuk melakukan pemanfaatan berikutnya.

Jumlah pasien yang memanfaatkan pelayanan rawat inap pada tahun 2012 tiap triwulannya terus meningkat, yakni pada triwulan pertama sebanyak 162 pasien, triwulan 2 sebanyak 399 pasien, triwulan 3 sebanyak 527 pasien dan triwulan 4 sebanyak 645 pasien (Rekam Medik Rumah Sakit Universitas Hasanuddin, 2012). Adanya keluhan pasien rawat inap, fluktuatifnya persentase kepuasan pasien rawat inap sedangkan jumlah pasien yang memanfaatkan pelayanan rawat inap tiap triwulannya terus meningkat maka penulis tertarik untuk meneliti lebih lanjut mengenai hubungan brand attitude (sikap terhadap merek) pasien rawat inap terhadap minat pemanfaatan kembali pelayanan di Rumah Sakit Universitas Hasanuddin..

\section{METODE PENELITIAN}

Penelitian ini dilaksanakan di Instalasi Rawat Inap Rumah Sakit Universitas Hasanuddin pada Tahun 2013. Sampel adalah pasien rawat inap yang dijumpai di lokasi penelitian yakni sebesar 120 orang. Pemilihan sampel dilakukan secara purposive sampling. Penelitian ini menggunakan rancangan survei analitik dengan pendekatan cross sectional study. Pengumpulan data diperoleh dengan dua cara, yakni data primer (hasil penyebaran kuesioner untuk mendapatkan informasi tentang komponen kognitif dan komponen afektif serta minat pemanfaatan kembali) dan data sekunder berupa profil rumah sakit, jumlah kunjungan, survey kepuasan, data keluhan pasien dan data lain yang terkait dengan penelitian ini. Data yang telah dikumpulkan kemudian diolah dan dianalisis dengan sistem komputerisasi program SPSS (Statistical Package for Social Science) 
dilakukan tabulasi silang dan uji statistik menggunakan uji korelasi spearman karena data tidak terdistribusi normal kemudian disajikan dalam bentuk tabel dan narasi. Peneliti melakukan penelitian dengan memperhatikan masalah etika meliputi Informed Consent, Anonimity, dan Confidentiality.

\section{HASIL PENELITIAN}

Tabel 1 menunjukkan distribusi umur responden bahwa dari 120 responden kelompok usia yang paling banyak berkunjung di Rumah Sakit Universitas Hasanuddin adalah kelompok usia 37-43 (42\%) dan paling sedikit adalah kelompok usia 65-71 (4,2\%). Jenis kelamin laki-laki sebesar 42 responden (35\%) sedangkan jenis kelamin perempuan sebanyak 78 (65\%). Berdasarkan tingkat pendidikan dari 120 responden yang paling banyak sebesar $32,5 \%$ yakni tamat S1 dan paling sedikit yakni tamat S3 sebesar 2,5\%. Pekerjaan yang banyak digeluti oleh responden yang berkunjung di Rumah Sakit Universitas Hasanuddin adalah PNS/TNI/POLRI sebesar 38,3\%, dan paling sedikit adalah petani/buruh sebesar 1,7\%. Sebagian besar responden berpendapatan antara Rp. 2.500.000 - Rp. 5.000.000,- yaitu sebesar $71,7 \%$ dan yang paling rendah yakni responden yang berpendapatan $\mathrm{Rp}<1.000 .000$ sebesar $1,7 \%$. Domisili responden yang paling banyak berkunjung di Rumah Sakit Universitas Hasanuddin adalah luar kota Makassar sebesar 52,5\% sedangkan dalam kota Makassar sebesar 47,5\%.

Berdasarkan tabel 2, kognitif dan afektif responden tergolong tinggi dan memiliki minat pemanfaatan kembali yang baik. Dari 120 responden yang memiliki kognitif tinggi sebesar $81,7 \%$ (98 responden) dan yang memiliki kognitif rendah sebesar 18,3\% (22 responden). Komponen afektif responden tergolong tinggi. Responden yang memiliki afektif tinggi sebesar 53,3\% (64 responden) dan yang memiliki afektif rendah sebesar $46,7 \%$ (56 responden). Dari 120 responden yang memiliki minat yang baik sebesar $83,3 \%$
(106 responden) dan yang memiliki minat yang kurang baik sebesar $11,7 \% \quad$ (14 responden).

Tabel 3 menunjukkan bahwa tingkat pendidikan tamat S3 yakni dari 3 responden keseleruhan memiliki komponen kognitif tinggi sebesar $100 \%$, tamat S1 dari 39 responden yang memiliki komponen kognitif rendah sebesar 30,8 dan tingkat pendidikan tamat S3 memiliki komponen afektif tinggi sebesar 66,7\% kemudian komponen afektif rendah ada pada responden dengan tingkat pendidikan tamat SD sebesar $66,7 \%$. Berdasarkan pendapatan responden yang memiliki komponen kognitif tinggi ada pada tingkat pendapatan Rp.2.500.000 keatas, pada tingkat pendapatan Rp.2.500.001-5.000.0000 memiliki komponen afektif tinggi sebesar $54,7 \%$ sedangkan komponen afektif rendah ada pada tingkat pendapatan Rp.5.000.0017.500 .000 sebesar $57,1 \%$. Mayoritas responden menggunakan jenis pembayaran Askes.

Tabel 4 diketahui bahwa responden yang memiliki komponen kognitif tinggi memiliki minat pemanfaatan yang baik sebesar $92,9 \%$ dan minat kurang baik $7,1 \%$ kemudian responden yang memiliki komponen kognitif rendah memiliki minat baik sebesar $68,2 \%$ dan minat kurang baik $31,8 \%$, responden yang memiliki komponen afektif tinggi memiliki minat pemanfaatan yang baik sebesar $93,8 \%$ dan minat kurang baik $6,2 \%$ kemudian responden yang memiliki komponen afektif rendah memiliki minat baik sebesar $82,1 \%$ dan minat kurang baik $17,9 \%$.

Tabel 5 menunjukkan variable komponen kognitif menunjukkan signifikansi sebesar $0.001(\mathrm{p}<0,05)$, maka hal ini berarti komponen kognitif signifikan memiliki hubungan terhadap minat pemanfaatan kembali pelayanan di Rumah Sakit Universitas Hasanuddin. Variabel komponen afektif menunjukkan signifikansi sebesar 0.049 $(\mathrm{p}<0,05)$, maka hal ini berarti komponen afektif signifikan memiliki hubungan terhadap minat pemanfaatan kembali pelayanan di Rumah Sakit Universitas Hasanuddin. 
Tabel 1 Distribusi Karakteristik Responden Di Rumah Sakit Universitas Hasanuddin Tahun 2013

\begin{tabular}{|c|c|c|}
\hline Karakteristik & n & $\%$ \\
\hline \multicolumn{3}{|l|}{ Kategori Umur } \\
\hline 16-22 tahun & 13 & 10,8 \\
\hline 23-29 tahun & 12 & 10,0 \\
\hline 30-36 tahun & 18 & 15,0 \\
\hline 37-43 tahun & 24 & 20,0 \\
\hline 44-50 tahun & 14 & 11,7 \\
\hline 51-57 tahun & 21 & 17,5 \\
\hline 58-64 tahun & 13 & 10,8 \\
\hline 65-71 tahun & 5 & 4,2 \\
\hline \multicolumn{3}{|l|}{ Jenis Kelamin } \\
\hline Laki-laki & 42 & 35,0 \\
\hline Perempuan & 78 & 65,0 \\
\hline \multicolumn{3}{|l|}{ Tingkat Pendidikan } \\
\hline Tamat SD/sederajat & 9 & 7,5 \\
\hline Tamat SMP/sederajat & 8 & 6,7 \\
\hline Tamat SMA/sederajat & 36 & 30,0 \\
\hline Tamat Diploma & 14 & 11,7 \\
\hline Tamat S1 & 39 & 32,5 \\
\hline Tamat S2 & 11 & 9,2 \\
\hline Tamat S3 & 3 & 2,5 \\
\hline \multicolumn{3}{|l|}{ Pekerjaan } \\
\hline PNS/TNI/POLRI & 46 & 38,3 \\
\hline Pensiunan & 10 & 8,3 \\
\hline PNS/TNI/POLRI & 6 & 5,0 \\
\hline Pegawai Swasta & 18 & 15,0 \\
\hline Wiraswasta/pedagang & 2 & 1,7 \\
\hline Petani/buruh & 13 & 10,8 \\
\hline Pelajar/mahasiswa & 25 & 20,8 \\
\hline \multicolumn{3}{|l|}{ IRT/tidak bekerja } \\
\hline \multicolumn{3}{|l|}{ Pendapatan } \\
\hline Rp. $<1.000 .000$ & 2 & 1,7 \\
\hline Rp. $1.000 .000-2.500 .000$ & 24 & 20,0 \\
\hline Rp. 2.500.000-5.000.000 & 86 & 71,7 \\
\hline Rp. 5.000.000-7.500.000 & 7 & 5,8 \\
\hline Rp. $>7.500 .000$ & 1 & 0,8 \\
\hline \multicolumn{3}{|l|}{ Lokasi Tempat Tinggal } \\
\hline Dalam Kota Makassar & 57 & 47,5 \\
\hline (berdomisili $\leq 6$ bulan) & 63 & 52,5 \\
\hline Luar Kota Makassar & & \\
\hline Total & 120 & 100 \\
\hline
\end{tabular}

Sumber : Data Primer 
Tabel 2 Distribusi Responden Berdasarkan Komponen Kognitif, Komponen Afektif Dan Minat Pemanfaatan Kembali Di Rumah Sakit Universitas Hasanuddin Tahun 2013

\begin{tabular}{lcc}
\hline \multicolumn{1}{c}{ Variabel Penelitian } & n & \% \\
\hline Komponen Kognitif & & \\
$\quad$ Tinggi & 98 & 81,7 \\
$\quad$ Rendah & 22 & 18,3 \\
Komponen Afektif & & \\
$\quad$ Tinggi & 64 & 53,3 \\
$\quad$ Rendah & 56 & 46,7 \\
Minat Pemanfaatan Kembali & & \\
$\quad$ Baik & 106 & 88,3 \\
$\quad$ Kurang Baik & 14 & 11,7 \\
\hline Total & $\mathbf{1 2 0}$ & $\mathbf{1 0 0}$ \\
\hline Sul : Dat Primer
\end{tabular}

Sumber : Data Primer

Tabel 3 Tabulasi Silang Antara Tingkat Pendidikan dan Pendapatan, Dengan Komponen Kognitif Dan Komponen Afektif Di Rumah Sakit Universitas Hasanuddin Tahun 2013

\begin{tabular}{|c|c|c|c|c|c|c|c|c|}
\hline \multirow{3}{*}{ Kategori } & \multicolumn{4}{|c|}{ Variabel Kognitif } & \multicolumn{4}{|c|}{ Variabel Afektif } \\
\hline & \multicolumn{2}{|c|}{ Tinggi } & \multicolumn{2}{|c|}{ Rendah } & \multicolumn{2}{|c|}{ Tinggi } & \multicolumn{2}{|c|}{ Rendah } \\
\hline & $\mathbf{n}$ & $\%$ & $\mathbf{n}$ & $\%$ & $\mathbf{n}$ & $\%$ & $\mathbf{n}$ & $\%$ \\
\hline \multicolumn{9}{|l|}{ Tingkat Pendidikan } \\
\hline Tamat SD/sederajat & 8 & 88,9 & 1 & 11,1 & 3 & 33,3 & 6 & 66,7 \\
\hline Tamat SMP/sederajat & 7 & 87,5 & 1 & 12,5 & 5 & 62,5 & 3 & 37,5 \\
\hline Tamat SMA/sederajat & 32 & 88,9 & 4 & 11,1 & 17 & 47,2 & 19 & 52,8 \\
\hline Tamat Diploma & 11 & 78,6 & 3 & 21,4 & 7 & 50,0 & 7 & 50,0 \\
\hline Tamat S1 & 27 & 69,2 & 12 & 30,8 & 22 & 56,4 & 17 & 43,6 \\
\hline Tamat S2 & 10 & 90,9 & 1 & 9,1 & 8 & 72,7 & 3 & 27,3 \\
\hline Tamat S3 & 3 & 100 & 0 & 0 & 2 & 66,7 & 1 & 33,3 \\
\hline \multicolumn{9}{|l|}{ Pendapatan } \\
\hline Rp. $<1.000 .000$ & 2 & 100 & 0 & 0 & 1 & 50 & 1 & 50 \\
\hline Rp. $1.000 .000-2.500 .000$ & 18 & 75 & 6 & 25 & 12 & 50 & 12 & 50 \\
\hline Rp. 2.500.000-5.000.000 & 70 & 81,4 & 16 & 18,6 & 47 & 54,7 & 39 & 45,3 \\
\hline Rp. 5.000.000-7.500.000 & 7 & 100 & 0 & 0 & 3 & 42,9 & 4 & 57,1 \\
\hline Rp. $>7.500 .000$ & 1 & 100 & 0 & 0 & 1 & 100 & 0 & 0 \\
\hline Total & 98 & 81,7 & 22 & 18,3 & 64 & 53,3 & 56 & 46,7 \\
\hline
\end{tabular}

Sumber : Data Primer

Tabel 4 Tabulasi Silang Antara Komponen Kognitif Dan Komponen Afektif Dengan Minat Pemanfaatan Kembali Di Rumah Sakit Universitas Hasanuddin Tahun 2013

\begin{tabular}{lcccc}
\hline \multirow{2}{*}{ Variabel Penelitian } & \multicolumn{4}{c}{ Minat Pemafaatan Kembali } \\
\cline { 2 - 5 } & \multicolumn{2}{c}{ Baik } & \multicolumn{3}{c}{ Kurang Baik } \\
\cline { 2 - 5 } Komponen Kognitif & $\mathrm{n}$ & & $\mathrm{n}$ & $\%$ \\
$\quad$ Tinggi & 91 & 92,9 & 7 & 7,1 \\
$\quad$ Rendah & 15 & 68,2 & 7 & 31,8 \\
Komponen Afektif & & & 4 & 6,2 \\
$\quad$ Tinggi & 60 & 93,8 & 10 & 17,9 \\
$\quad$ Rendah & 46 & 82,1 & $\mathbf{1 4}$ & $\mathbf{1 1 , 7}$ \\
\hline Total & $\mathbf{1 0 6}$ & $\mathbf{8 8 , 3}$ & &
\end{tabular}

Sumber : Data Primer 
Tabel 5 Hubungan Kognitif dan Afektif terhadap Minat Pemanfaatan Kembali Di Rumah Sakit Universitas Hasanuddin Tahun 2013

\begin{tabular}{|c|c|}
\hline \multirow[t]{2}{*}{ Variabel Penelitian } & Minat Pemanfaatan Kembali \\
\hline & $\mathbf{P}$ \\
\hline Kognitif & 0,001 \\
\hline Afektif & 0,049 \\
\hline
\end{tabular}

Sumber : Data Primer

\section{PEMBAHASAN}

Ditinjau dari kelompok usia, responden yang paling banyak memanfaatkan rawat inap di Rumah Sakit Universitas Hasanuddin adalah kelompok usia 37-43 tahun, diikuti kelompok usia 51-57 tahun dan kelompok usia 30-36 tahun serta kelompok usia 44-50. Konsumen pada setiap jenjang usia tertentu cenderung memiliki kebutuhan yang berbeda. pada usia produktif (dewasa) sering terjadi gaya hidup yang tidak sehat, karena kebiasaan yang tidak sehat, mereka biasa melakukan aktivitas sampai malam hari, istirahat kurang, makan makanan tidak sehat dan kurang olahraga, sementara di usia anak dan atau remaja mereka belum berhak memutuskan sesuatu atas dirinya, dalam usia ini disebutkan bahwa seseorang berada dalam tahap pertumbuhan dalam hal fisik, psikis/emosional serta seksual menuju fase dewasa, mereka masih sering berubah karena pengaruh orang disekelilingnya berdasarkan referensi orang di sekitarnya dalam memberikan pendapatnya mengenai hal apapun dan biasanya mereka akan dibantu dengan terlibatnya orang dewasa (orangtua/keluarga) yang ada di sekitarnya (Anjaryani,2010).

Ditinjau jenis kelamin mayoritas yang memanfaatkan rawat inap di Rumah Sakit Universitas Hasanuddin adalah perempuan. Menurut Kotler (dalam Muhaimin 2011), jenis kelamin merupakan aspek utama yang penting diketahui perusahaan ketika menciptakan suatu produk. Adanya perbedaan jenis kelamin akan membentuk perilaku pembelian yang berbeda pula.

Ditinjau dari tingkat pendidikan responden yang paling banyak memanfaatkan rawat inap di Rumah Sakit Universitas Hasanuddin adalah tamat S1. Schiffman dan Kanuk (2008), mengemukakan bahwa tingkat pendidikan formal seseorang itu merupakan perkiraan lain bagi kedudukan kelas sosial yang umum diterima, sehingga semakin tinggi pendidikan seseorang, semakin besar kemungkinan orang bergaji tinggi serta semakin jeli dan cerdas konsumen melihat kondisi produk atau jasa yang ditawarkan. (Anggraeny,2009) setiap jenjang pendidikan menciptakan individu dengan kemampuan kognitif yang berbeda yang mempengaruhi seseorang dalam mempersepsikan suatu objek.

Dari segi pekerjaan responden yang paling banyak memanfaatkan pelayanan rawat inap di Rumah Sakit Universitas Hasanuddin, pekerjaan yang menduduki urutan pertama adalah PNS/TNI/Polri dan ibu rumah tangga kebanyakan dari mereka berada pada usia 1545 yang merupakan usia produktif, sehingga hal ini menunjukan menyadari akan kecenderungan untuk memperbaiki dan meningkatkan derajat kesehatannya.

Dari segi tingkat pendapatan / penghasilan responden yang memanfaatkan pelayanan rawat inap Rumah Sakit Universitas Hasanuddin didominasi oleh responden yang memiliki tingkat pendapatan Rp. 2.500.000 Rp. 5.000.000. Hal ini menunjukkan bahwa sebagian besar responden Rumah Sakit Universitas Hasanuddin adalah tingkat golongan ekonomi menengah ke atas. Faktor penghasilan akan sangat mempengaruhi seseorang dalam setiap keputusannya, tingkat penghasilan konsumen akan mempengaruhi mereka dalam pemanfaatan pelayanan kesehatan. Berdasarkan penelitian Muhaimin (2011), tingkat pendapatan seseorang akan mempengaruhi daya belinya, sehingga juga akan mempengaruhi barang dan jasa yang 
dibelinya semakin tinggi tingkat pendapatan, maka semakin tinggi pula kemampuan membeli seseorang.

Ditinjau lokasi tempat tinggal responden yang memanfaatkan rawat inap Rumah Sakit Universitas Hasanuddin paling banyak adalah berada pada wilayah luar kota Makassar. Menurut Kotler dan Keller (2009) bahwa salah satu yang mempengaruhi konsumen memutuskan memanfaatkan produk dan jasa adalah Marketing Mix yang khususnya Place. Konsumen yang kebiasaannya ingin praktis, lokasi atau tempat menjadi pilihan utama untuk mengakses produk atau jasa, akan tetapi berbeda dengan pasien Rumah Sakit Universitas Hasanuddin bahwa lokasi tidak mempengaruhi pasien dalam memanfaatkan pelayanan kesehatan. Berdasarkan hasil wawancara yang dilakukan oleh pasien itu sendiri bahwa faktor yang mendorong pasien memanfaatkan layanan kesehatan adalah kelengkapan fasilitas dan tenaga yang professional.

Berdasarkan hasil penelitian diperoleh bahwa responden termasuk pada kategori memiliki komponen kognitif tinggi mengenai Rumah Sakit Universitas Hasanuddin, hal ini menunjukkan bahwa ada informasi yang telah tersebar mengenai Rumah Sakit Universitas Hasanuddin. Komponen kognitif adalah pengetahuan konsumen, yang diperoleh melalui pengalaman dengan suatu objek sikap dan infomasi dari berbagai sumber. Pengetahuan dan persepsi yang ditimbulkannya biasanya mengambil bentuk kepercayaan, yaitu kepercayaan konsumen bahwa objek sikap mempunyai berbagai sifat dan perilaku tertentu akan menimbulkan hasilhasil tertentu (Schiffman, Kanuk 2008, p225).

Pada Kategori Komponen Afektif, responden berada pada kategori tinggi, hal ini menunjukkan bahwa apa yang dirasakan oleh responden ketika dirawat di Rumah Sakit Universitas Hasanuddin sudah baik dari sisi sarana pendukung fisik dan kualitas hubungan pegawa dan pasien. Fasilitas yang dilihat konsumen merupakan bagian dari wujud nyata yang penting atas keseluruhan jasa yang ditawarkan tata letak ruang adalah desain dan pengaturan dari bangunan, peralatan, dan meubel sesuai kebutuhan proses layanan (Citraluki (2016), Sukardi (2016), Wicaksono (2013), dalam penelitiannya mengungkapkan bahwa keterlibatan dan pemberdayaan karyawan memiliki pengaruh positif terhadap kepuasan pelanggan.

Pada responden yang memiliki komponen kognitif tinggi memiliki minat pemanfaatan kembali yang baik untuk memanfaatkan kembali pelayanan di Rumah Sakit Universitas Hasanuddin, pada responden yang memiliki komponen kognitif rendah juga memiliki minat yang baik untuk memanfaatkan kembali pelayanan di Rumah Sakit Universitas Hasanuddin, dikarenakan Rumah Sakit Universitas Hasanuddin masih tergolong baru, informasi mengenai rumah sakit tersebut masih kurang bagi masyarakat di luar kota Makassar, dan beberapa orang yang telah merasakan pelayanan di rumah sakit tersebut meskipun dari luar kota Makassar mereka cenderung untuk berminat memanfaatkan kembali pelayanan di Rumah Sakit Universitas Hasanuddin.

Menurut Anderson (1997), pengetahuan dan keyakinan individu mempengaruhi individu tersebut untuk mengambil keputusan dan bertindak dalam menggunakan pelayanan kesehatan yang tersedia. Faktor yang mendukung seseorang dalam memilih layanan kesehatan adalah faktor pengetahuan (Hariyanti,2015). Pada komponen afektif yakni berdasarkan apa yang dirasakan oleh konsumen di Rumah Sakit Universitas Hasanuddin, responden yang memiliki afektif tinggi memiliki minat pemanfaatan kembali yang baik, begitu pula pada konsumen yang komponen afektif yang rendah mereka juga memiliki minat pemanfaatan kembali yang baik untuk memanfaatkan pelayanan di Rumah Sakit Universitas Hasanuddin.

Adanya responden yang memiliki minat kurang baik dalam memanfaatkan kembali pelayanan di Rumah Sakit Universitas Hasanuddin dikarenakan ada beberapa responden di luar pulau Sulawesi sehingga 
mereka lebih cenderung ke rumah sakit yang dekat dari tempat tinggalnya, kemudian juga terdapat responden yang memang tidak mendapatkan apa yang diharapkannya selama di Rumah Sakit Universitas Hasanuddin, kemudian dari sisi minat informasi hanya sedikit responden yang ingin mencari tahu kembali mengenai Rumah Sakit Universitas Hasanuddin itu sendiri di masa yang akan datang. Penelitian Bentler 1981 (dalam Kurniawati 2009) adanya perilaku masa lampau yang dapat mempengaruhi minat secara langsung dan perilaku mengkonsumsi ulang pada waktu yang akan datang.

\section{KESIMPULAN}

Terdapat hubungan antara kognitif dan afektif terhadap minat pemanfaatan kembali pelayanan di Rumah Sakit Universitas Hasanuddin. Pihak rumah sakit perlu melakukan survey kepada konsumennya mengetahui karakteristik dari para pengguna jasa pelayanan kesehatannya misalnya dari segi tingkat pendidikan dan pendapatan sehingga dapat mengetahui perilaku konsumennya dan menerapkan strategi pemasaran yang tepat. Perlu dilakukan penyebaran informasi mengenai keberadaan Rumah Sakit Universitas Hasanuddin pada wilayah di luar kota makasar karena pada saat penelitian rumah sakit ini masih tergolong baru, informasi tentang rumah sakit misalnya bisa melalui akses internet dengan mengembangkan website ataupun sosial media lainnya. Terus meningkatkan kualitas pelayanan di rumah sakit sehingga pasien memiliki kesan yang baik atas rumah sakit tersebut misalnya melalui pemberian pelatihan kepada SDM sehingga mereka lebih kompeten dalam bekerja. Pada sarana pendukung fisik seperti fasilitas parkir dan beberapa fasilitas di ruang perawatan juga perlu dilengkapi.

\section{REFERENSI}

Anderson, David R. (1997). Manajemen Pendekatan Kuantitatif untuk pengambilan keputusan manajemen. Jakarta:Erlangga

Anggraeny, Muthia Octora. (2009).Gambaran Persepsi Pegawai Non Medis Terhadap Komponen Quality Of Work Life Di Rumah Sakit Islam Jakarta Cempaka Putih. Depok : Universitas Indonesia

Anjaryani. (2009). Kepuasan Pasien Rawat Inap Terhadap Pelayanan Perawat Di RSUD Tugurejo Semarang. Universitas Diponegoro : Semarang.

Citraluki, Jaeqline. (2016). Pengaruh Penerapan Total Quality Management (TQM) Terhadap Kepuasan Pelanggan Pada Indomaret Sekecamatan Kartasura Tahun 2016. Universitas

Muhammadiyah Surakarta. : Solo.

Customer Care. (2012). Data Jumlah Keluhan Pasien Rawat Inap. RS Unhas: Makassar

Hariyanti T, Harsono, Prabandari Y. (2015) Seeking Behaviour pada Pasien Stroke. Jurnal Kedokteran Brawijaya. 28(3): 242-246.

Hospital Safety. (2012). Survei Kepuasan Pasien Rawat Inap Tahun 2012.RS Unhas: Makassar

Kotler, P dan Kevin Lane Keller. (2009). Manajemen Pemasaran, Ed. 13, Jilid 1. Penerbit Erlangga: Jakarta

Kurniawati, Dyah. (2009). Studi Tentang Sikap Terhadap Merek Dan Implikasinya Pada Minat Beli Ulang. Univesitas Diponegoro : Semarang Online. Diperoleh dari [http://eprints.undip.ac.id/17223/1/Dya h_Kurniawati.pdf].

Muhaimin, wahid. (2011). Consumer's Behaviour in Purchasing the Red Rosella Tea in Malang City. Universitas Brawijaya : Malang

Octiani,Ika.(2008). Analisis Faktor Yang Mempengaruhi Sikap Terhadap Merek. Universitas Diponegoro : Semarang : Online Diperoleh dari [http://eprints.undip.ac.id/17740/1/IKA _OKTIANI_CHOERUNNISA.pdf] 
Rekam Medik.(2012). Jumlah pasien rawat inap.RS Unhas : Makassar

Schiffman, L dan Leslie Lazar Kanuk. (2008) Perilaku Konsumen, Edisi Ketujuh. Penerbit PT Indeks: Jakarta

Sukardi, Amalia. (2016). Pengaruh Total Quality Management (TQM) Terhadap Kepuasan Pelanggan Pada Matahari Department Store di Plaza Muria Samarinda.

Wicaksono, Hendra Dwi. (2013). Pengaruh Penerapan Total Quality Management (TQM) Terhadap Kepuasan Pelanggan Pada Karaoke NAV Daerah Kecamatan Jebres Surakarta Tahun 2013. Universitas Muhammadiyah Surakarta. : Solo. 